\title{
A EDUCAÇÃO PARA O EMPREENDEDORISMO (EE) CONTRIBUI PARA O DESENVOLVIMENTO DA CARREIRA? UMA PERSPECTIVA DE EGRESSOS DE UM PROGRAMA DE EDUCAÇÃO EMPREENDEDORA
}

Flávia Alexandrina Coelho Marcos ${ }^{1}$

Sandra Regina Holanda Mariano ${ }^{1}$

${ }^{1}$ Universidade Federal Fluminense 


\section{A EDUCAÇÃO PARA O EMPREENDEDORISMO (EE) CONTRIBUI PARA O DESENVOLVIMENTO DA CARREIRA? UMA PERSPECTIVA DE EGRESSOS DE UM PROGRAMA DE EDUCAÇÃO EMPREENDEDORA}

Resumo: A promoção da educação para o empreendedorismo (EE) voltada para o público adulto vem se constituindo em uma estratégia para o desenvolvimento de competências que proporciona ao indivíduo repensar-se e reposicionar-se profissionalmente. A literatura do campo de EE aponta uma lacuna no que se refere a estudos que avaliem a sua contribuição no longo prazo. Este artigo busca preencher esta lacuna ao identificar e analisar a contribuição de um programa de educação para empreendedorismo (PEE), transcorrido cinco anos de sua conclusão. Um survey foi enviado para os participantes do Curso Sequencial de Complementação de Estudos em Empreendedorismo e Inovação da Universidade Federal Fluminense, obtendo-se 173 respostas válidas. Os egressos destacaram que o PEE os despertou para a busca de novos desafios, novas ideias, melhorou as habilidades de comunicação e de lidar com mudanças, ampliou a visão sobre o mercado de trabalho e contribuiu para elevar a atratividade do currículo.

Palavras-chave: Educação empreendedora. Empreendedorismo. Carreira. Avaliação.

\section{Introdução}

No Brasil, desde o início da década de 1990, pesquisas no campo do empreendedorismo vêm ganhando cada vez mais importância (MORAES, 2016). O impulso dos indivíduos para o crescimento e a inovação está relacionado com a educação para o empreendedorismo (LANDSTRÖM, 2012). Para Lackéus (2015, p. 6) o papel central do empreendedor na sociedade é gerar valor para outras pessoas, o que é uma competência desejada para todos os cidadãos, independente da escolha de carreira. Neste sentido, a criação de empresa é uma das possibilidades, mas não a única, do indivíduo empreendedor.

Entendendo que a educação para o empreendedorismo fomenta atitudes que estimulam o desenvolvimento econômico e social, parte-se da premissa de que as pessoas podem ser educadas para empreender, ampliando suas possibilidades de realização profissional (FILION, 2004; MORAES, 2012). Além disso, os programas de Educação Empreendedora (PEE) contribuem para o desenvolvimento de competências importantes, tais como a persistência e a autoeficácia (FAYOLLE, 2015), atributos amplamente valorizados no mercado de trabalho.

No contexto de crescente valorização das competências empreendedoras, as quais podem ser desenvolvidas por meio de PEE, Fayolle (2015) aponta uma lacuna na literatura deste campo de pesquisa, a saber: a insuficiência de avaliação da eficácia de diferentes tipos de programas de empreendedorismo, especialmente transcorridos certo tempo após a realização do curso. Em 2005, o pesquisador norte americano, Zhao (2005) já indicava a necessidade de avaliar a eficácia dos programas de empreendedorismo, e Gibb (1993), mais de uma década antes, entendia como relevante avaliar a eficácia dos PEE estudando mudanças de atitudes e percepções dos egressos.

Nos últimos anos, observou-se ampliação significativa da oferta de programas de educação empreendedora sem que a eficácia ou mesmo a percepção sobre a contribuição de 
tais programas na perspectiva dos egressos tenha atraído maior atenção dos pesquisadores. Reconhecendo que a oferta de programas de EE tem se ampliado de forma consistente e considerável nos últimos anos, especialmente no Brasil, é fundamental ampliar a compreensão sobre as contribuições de tais programas para o público ao qual foi destinado.

No contexto brasileiro é importante observar a contribuição dos PEE, visto que há transformação da estrutura do emprego, com redução de vagas de emprego formal, há ampliação de modelos de contrataçao alternativos como o Microempreendedor Individual (MEI). Com a crecente de pessoas desocupadas, que em agosto/2019 somava 12,8 milhões de pessoas, é observado o aumento de trabalhadores por conta própria que em seis meses aumentou mais de 6,5\%, segundo o PNAD (2019), e bateu novo recorde da série histórica.

Assim, este artigo visa contribuir para uma melhor compreensão sobre em que e como um programa de educação empreendedora, voltado ao público adulto, contribuiu para o desenvolvimento de suas carreiras. Trata-se de uma forma indireta de avaliar quão eficaz foi o PEE na ótica daqueles que viveram a experiência.

\section{Referencial Teórico}

\subsection{Educação empreendedora e carreira}

Os esforços para prover a educação para o empreendedorismo (EE) vêm crescendo no mundo inteiro e nos diversos segmentos de ensino, desde a educação básica até o nível universitário e educação de adultos, conforme observado por Fayolle (2013). Para Lackéus (2015, p. 6), o papel central do empreendedor na sociedade é gerar valor para outras pessoas, sendo uma competência desejada para todos os cidadãos, independente da escolha de carreira. Neste sentido, a criação de empresa é uma das possibilidades, mas não a única, do indivíduo empreendedor.

Programas voltados para a educação empreendedora (PEE) impactam nas intenções empreendedoras, que se relacionam a propensão do indivíduo para empreender (FAYOLLE, 2015). Assim, os PEEs contribuem para o desenvolvimento do comportamento empreendedor e para o desenvolvimento de competências importantes, tais como a persistência e a autoeficácia (FAYOLLE, 2015). Com o crescimento destes programas, surge a discussão sobre a necessidade de avaliá-los. Para Zao (2005), os estudos que se dedicam a avaliar o impacto da EE são escassos, apesar dos esforços de pesquisadores como Kakouris (2008) que, ao avaliar os PEE, identificou a necessidade de formar profissionais para trabalhar a EE.

Pesquisa realizada por Duval-Couetil (2012) com egressos de um PEEs apontou para o desenvolvimento de novas habilidades que podem contribuir para a ampliação da perspectiva da escolha de carreira. Para Kolade (2018), os PEE estão relacionados com mudança positiva da mentalidade e com desenvolvimento e criação de novos empreendimentos (DUVALCOUETIL, 2012). Elmuti (2012), ao analisar variáveis para medir a eficácia organizacional, como desempenho e satisfação com os objetivos da empresa observou impacto positivo da EE nos cursistas e também observou maiores níveis de interações sociais e reflexões que estimulam a criatividade. Foi percebido que os participantes dos PEE foram impactados, principalmente no desenvolvimento de competências sociais.

A mentalidade empreendedora, incluindo o aumento da autoeficácia e a escolha de carreira empreendedora, também são apresentadas como uma das características desenvolvida pela EE (DUVAL, 2013). Os participantes do PEE afirmaram que a EE os ajudou a conquistar 
um emprego e tornar o currículo mais atrativo, elementos importantes para o desenvolvimento de carreira (DUVAL, 2013). Keena (2015) também afirma que há contribuição dos PEE para a empregabilidade. Já Arpiainen (2017) conclui que a EE tem uma natureza transformadora e pode desenvolver competências voltadas para correr riscos e relaciona o benefício do trabalho em equipe para elevar a capacidade de correr risco e lidar com incerteza.

Massi (2013) entende que o maior benefício do PEE é o desenvolvimento da personalidade profissional, como as habilidades de trabalhar em equipe e Carvalho(2015), também, ressalta a criação e a capacidade de trabalhar em equipe como um fator positivo do PEE e sua influência no projeto de vida das pessoas, envolvendo dimensões pessoais e profissionais. Após exposição a um PEE, a capacidade criativa do indivíduo é estimulada (PEDRINI, 2017), o que está em concordância com Kovesi (2017) que apresenta a criatividade como importante para o desenvolvimento da EE. É percebido que um PEE contribui para a escolha do empreendedorismo como opção de carreira (DIAZ-GARCIA, 2015).

\subsection{Carreira empreendedora}

O conceito de carreira surgiu no século XIX com a sociedade industrial capitalista liberal e define uma profissão ou um percurso profissional (CARREIRA, 2016). A carreira envolve as dimensões pessoal e profissional (CALLANAM, 2016). Quais carreiras e para qual sociedade? Esta foi a pergunta feita por Chalant (1996) há quase 25 anos, que permanece atual. Os fenomenos por ele identificados como diminuição das ofertas de empregos formais, o avanço dos trabalhos temporários e a diminuição dos empregos disponíveis se intensificaram e ampliaram os desafios a serem enfrentados pelos que desejam fazer carreira. Diante deste cenário, surge o conceito de "carreira sem fronteira".

A "carreira sem fronteira" é um conceito que tem ligação com a carreira empreendedora, devido as características do indivíduo se assemelhar as apresentadas na carreira empreendedora (ARTHUR, 1996). Neste tipo de carreira não há uma visão tradicional, baseada na relação de emprego de longo prazo, e a trajetória profissional não é previsível (MIRVIS, 1996). Os trabalhadores se identificam com as funções exercidas (ARTHUR, 1996). Já a carreira empreendedora é aquela que se desenvolve no âmbito das pequenas e médias empresas, empresas artesanais, culturais, comunitárias, de caridade e se relaciona com a sociedade que valoriza a iniciativa individual, conforme propõe Chanlat (1996). Para Greenhaus (2010, p. 284), o empreendedor é uma pessoa com "tendência a reconhecer e capitalizar as oportunidades de mercado", enquanto Callanam (2016), ressalta que é uma carreira reconhecida pela criação de empregos e auxílio social.

É entendido que as pessoas podem empreender a partir da abertura do próprio negócio, sendo empreendedores empresariais, ou podem empreender com a premissa de mudança da realidade social no seu entorno, sendo empreendedores sociais. Outro tipo de empreendedor são os intraempreendedores, que atuam dentro de uma organização constituída contribuindo com algo criativo, ou seja, dotados de atitudes e comportamentos empreendedores (FILION, 2004; MORAES, 2012). O intraempreendedorismo é visto como uma alternativa para a busca da inovação e resulta na lucratividade e competitividade (BARUAH, 2015).

Observando a personalidade dos intraempreendedores, foi percebido que o indivíduo que melhor se adapta a carreira tem mais propensão de ser um intraempreendedor (WOO, 2018). Para Woo (2018), a adaptabilidade de carreira é observada a partir de como os 
funcionários lidam com novas demandas de trabalho. Além disso, o intraempreendedorismo é associado a inovação (CHAN, 2017). Para Farruk (2016), a abertura a experiências é positiva ao intraempreendedorismo, visto que o indivíduo com abertura a experiências é imaginativo, de mente aberta, curioso, não tradicional, busca novas ideias e soluções. Os indivíduos com doutorado são menos propensos ao empreendedorismo (DOUGLAS, 2013), assim como as instituições públicas são menos intraempreendedoras do que as privadas (LAGES, 2017).

Quem decide empreender precisa desenvolver as competências empreendedoras para aumentar as chances de que o empreendimento seja bem sucedido. As características psicológicas dos empreendedores foram estudadas por diferentes pesquisadores, como McCleland (1987) e também abordados por Lee-Ross (2015), que identificou competências importantes para o perfil empreendedor, como a independência, assunção de risco e criatividade. O impulso dos indivíduos para o crescimento e a inovação está relacionado com a EE (LANDSTRÖM, 2012), sendo a geração de ideias novas importante para o desenvolvimento dos setores da sociedade (MOBERG, 2014).

\section{Procedimentos metodológicos}

A presente pesquisa foi dividida em três etapas. Na primeira etapa, exploratória, foram realizadas revisões de literatura sobre os temas: educação empreendedora e carreira; desenvolvimento de carreira; carreira empreendedora; competências empreendedoras e carreira e intraempreendedorismo, que forneceram os subsídios para elaboração do referencial teórico e construção do instrumento de coleta de dados. Já a segunda etapa foi caracterizada pela construção e validação do questionário. O questionário foi composto por 80 afirmações usando a escala Likert. Entre as afirmações foram propostas duas questões abertas que buscavam entender as três principais contribuições do curso para a vida pessoal e profissional do egresso e a mudança na vida dos respondentes.

A parte 1 do questionário serviu à caracterização da amostra. Já a parte 2 relaciona a percepção do egresso sobre a contribuição do curso de Empreendedorismo e Inovação para a sua carreira. Outro bloco de questões foi destinado aos egressos do curso que atuavam como colaboradores em organizações estabelecidas e buscava-se compreender como o programa contribuiu na sua atuação corporativa. O último bloco de questões buscou avaliar a percepção do egresso sobre a contribuição de um PEE para o desenvolvimento de competências, incluindo as competências de organização, gestão de risco, gestão de pessoas; competências de relacionamento e competência de oportunidade, temas que estavam relacionados com as disciplinas do programa. Para esta parte 4, utilizou-se a escala proposta por Carvalho (2004) apud Makhamed (2017).

O instrumento de coleta de dados foi testado por dez pessoas. Não houve alteração no questionário após o pré-teste. A amostra necessária para se obter um nível de confiança de $95 \%$ e margem de erro de $5 \%$, de modo a representar a população, foi calculada segundo Hair Jr. et. al (2009), obtendo-se o valor de 105. O questionário foi disponibilizado para os respondentes através da plataforma SurveyMonkey e foi enviado para os egressos por e-mail inicialmente em novembro de 2018 e ficou disponível para os respondentes por 55 dias. Os envios ocorreram mais de uma vez. Houve mais quatro datas de envio subsequentes.

Das questões abertas, uma objetivava aprofundar o entendimento sobre a contribuição do curso para o indivíduo e outra que buscava saber sobre as mudanças na vida do egresso. A 
análise de conteúdo das questões abertas deste estudo foi realizada a partir da leitura do texto. Foi utilizado o método da categorização de Bardin (2006) cujo objetivo é classificar os elementos, criando rubricas significativas e procurando introduzir uma ordem nas mensagens. Foi realizada uma primeira leitura das respostas, onde emergiram as categorias. Posteriormente, foi realizada nova leitura para a categorização de cada resposta, onde foram tabeladas todas as respostas apresentadas e observadas semelhanças entre elas. Cada cursista foi codificado como C1 a C173 e as respostas como R1 a R80.

\section{O programa de educação para o empreendedorismo}

O Curso Sequencial de Complementação de Estudos em Empreendedorismo e Inovação foi desenvolvido pela Universidade Federal Fluminense (UFF), ofertou 600 vagas, gratuitas, no segundo semestre de 2012 aos municípios de Angra dos Reis, Itaperuna, Macaé, Niterói, Paracambi, Resende, Rio Bonito e Volta Redonda (LOPES, 2017). O público-alvo do curso foi graduandos ou graduados de todas as áreas profissionais. Para o preenchimento das vagas, houve um processo seletivo constituído de 40 (quarenta) questões de múltipla escolha.

$\mathrm{O}$ curso adotou metodologia semipresencial, com encontros presenciais realizados em pólos regionais a cada dois meses. Foi utilizado o AVA Moodle para a realização de tutoria à distância, que se utiliza de atividades de fóruns, chats, entre outros. Foram ministradas as seguintes disciplinas: 1. Criatividade e Atitude Empreendedora; 2.Técnicas de Comunicação e Negociação; 3.Estratégia e Marketing para Empreendedores; 4. Gestão Empreendedora por Processos; 5.Gestão de Pessoas; 6.Finanças para Novos Empreendimentos e 7.Plano de Empreendimento. Foi desenvolvido material didático específico para o curso, disponível para o estudante em mídia impressa e digital. O curso contou com dois tipos de avaliações da aprendizagem: avaliação presencial e avaliação a distância. O projeto pedagógico do curso definiu como objetivo principal capacitar pessoas para atuar em situações complexas do cotidiano e buscar empreender em soluções inovadoras e, para isso, as disciplinas somavam 270 horas de aula distribuídas em quatro semestres. A oferta das disciplinas ocorreu por semestre letivo e as cargas horárias variam de $30 \mathrm{~h}$ ou $60 \mathrm{~h}$.

\section{Análise dos resultados}

Considerando a amostra de 173 respondentes, 95 eram homens $(54,9 \%)$ e 78 mulheres $(45,1 \%)$ e quase $40 \%$ dos respondentes encontravam-se entre 25 e 34 anos, e apenas $27 \%$ tinham acima de 46 anos. Foram 77 egressos que se declararam casados (44,5\%), seguidos de 75 indivíduos solteiros $(43,4 \%)$. Mais da metade dos respondentes $(55 \%)$ se declaram brancos e apenas $12,7 \%$ negros. Um total de 115 respondentes não tinham sido expostos a nenhuma experiência de EE até ingressar no curso (66,5\%). Dos respondentes, 50,3\% concluíram o curso, enquanto $49,7 \%$ completaram $80 \%$ da carga horária. Quanto a frequência sobre escolaridade do estudante no ingresso do curso, foi identificado que $49,1 \%$ dos respondentes, no momento em que ingressaram no curso, não tinham completado o ensino superior, enquanto $37 \%$ tinham o ensino superior completo e 13,9\% tinham pós-graduação.

Ao perguntar ao egresso sobre a sua ocupação no ingresso do curso foi identificado que a maior parte dos respondentes, 64,2\%, estavam empregados. Apenas aproximadamente $18 \%$ atuavam como autônomo, sócio de empresa privada ou microempreendedor. Foram observadas alterações na ocupação da maior parte dos respondentes em relação a 2012. A 
ocupação que teve maior alteração relativa foi de MEI (Microempreendedor individual), que passou de 7 para 14 indivíduos. O curso abordou o ambiente para empreender e discutiu a figura do MEI. Importante destacar que no período 2015/2016 o Brasil viveu uma forte recessão, elevação do desemprego e aumento expressivo do número de MEI. Outro item que apresentou aumento foi o de empregado do setor público que passou de $50(28,9 \%)$ para 60 pessoas no fim do curso $(34,7 \%)$. O PEE propôs o desenvolvimento de competências como a busca de oportunidades para empreender. É surpreendente, portanto, observar um aumento no número de empregados públicos, notadamente uma atividade reconhecida como de baixo risco e elevada estabilidade. Além disso, o perfil preponderante do funcionário público não parece ser de empreendedor, havendo, inclusive, estudos que sugerem que os servidores públicos são menos propensos a atuarem como intraempreendedores (RIBEIRO, 2013; LAGES, 2017). Embora seja inesperado o aumento de pessoas em cargo público após a conclusão do PEE, é importante destacar que o PCC do curso propõe potencializar o cursista no mercado de trabalho e a obtenção de um cargo público pode ser caracterizada como um avanço do cursista, visto que a função pública parece ser desejada por muitas pessoas no Brasil, tendo em vista a elevadíssima taxa de concorrência por vaga. Neste sentido, as competências gerenciais desenvolvidas no âmbito do curso podem ter contribuído para elevar a competitividade dos egressos nos concursos públicos.

Perguntou-se ao egresso "O que mudou na sua vida ou no seu trabalho após o curso de Empreendedorismo e Inovação?”, obtendo-se 142 respostas válidas. Foi observado que 62,9\% dos repondentes egressos do programa identificaram mudanças na própria vida ou no trabalho após a conclusão do curso. Este resultado está em linha com Duval (2013), que afirma que os PEE ajudam os seus participantes conquistarem um emprego e tornar o currículo mais atrativo, além de aumentar a predisposição para abrir um negócio e escolher o empreendedorismo como carreira. Embora $62,9 \%$ dos respondentes tenham identificado mudanças na vida pessoal ou profissional, pouco mais de $1 / 3$, ou seja $35,7 \%$, foram promovidos na empresa em que trabalhavam. Aproximadamente $1 / 4$ dos respondentes informam administrar um negócio próprio ou fundado uma ONG. Possivelmente, as atividades do curso contribuíram para a estruturação de um empreendimento, corroborando os achados de Diaz-Garcia (2015), que afirma que o PEE contribuiu para a escolha do empreendedorismo como opção de carreira para alguns cursistas.

Para aprofundar o entendimento sobre a contribuição do curso para o indivíduo empregado de empresa privada ou pública foi realizada uma questão aberta, a saber: "Sintetize as três principais contribuições do curso para a sua vida pessoal e profissional". A pergunta envolve as dimensões pessoal e profissional, pois a carreira compreende uma visão multidisciplinar que envolve as diversas áreas da vida (CALLANAM, 2016). Foram obtidas 41 respostas válidas, ou seja, quase $40 \%$ dos respondentes empregado público ou privado. Foi possível observar que 58,0\% dos respondentes destacaram a contribuição do curso para o trabalho, enquanto $36,2 \%$ destacaram a contribuição para a vida pessoal, e outros $5,7 \%$ deram respostas não relacionadas ao tema perguntado. Foi possível coletar declarações como:

"O curso estimulou o desenvolvimento da capacidade de mudar, de fazer o novo e de buscar novos desafios! Foi muito agregador! Hoje ministro palestras, minicursos, além de atuar no ensino superior, profissional e cursos regulares. Gratidão!” (C79.25). 
Os respondentes que apontaram a contribuição do PEE para a vida pessoal relacionaram o desenvolvimento de competências, tais como: capacidade de promover mudanças, busca de novas ideias, identificação de oportunidade, autoconhecimento e melhoria contínua, entre outras. Mudanças de habilidades como melhoria na comunicação e síntese de ideias também foram citadas. Destacam-se afirmações dos respondentes:

"O curso estimulou o desenvolvimento da capacidade de mudar, de fazer o novo e de buscar novos desafios" (C79.25).

"Identificação de oportunidades, Pensar fora da caixa, Vontade de vencer" (C50.25)

"Aprendi a me comunicar melhor tanto no pessoal quanto no profissional, a sintetizar melhor as ideias, a me planejar melhor" (C116.25).

Ao analisar a contribuição do curso para a vida profissional, de maneira geral, os egressos parecem concordar que o programa promoveu a ampliação da visão para o mercado de trabalho. Esta percepção pode ser ilustrada nas respostas abaixo:

"Encaro o processo de trabalho com uma visão mais empreendedora e com maior fundamentação nas ações que tomo" (C96.25).

"Mudança de visão do mercado; Trabalho em equipe e Superar desafios" (C11.25)

Foi proposto que os egressos respondessem outra questão aberta sobre as mudanças na vida, a saber: "Descreva o que mudou na sua vida que não está listado acima". A questão foi proposta devido o entendimento que a $\mathrm{EE}$ pode mudar a vida do indivíduo em diversas dimensões. Em uma análise sobre as respostas, observou-se 38 respostas e a grande maioria das respostas, 91,8\%, apresentou percepções positivas da contribuição do curso para a vida. Abordagens como a contribuição do PEE para os negócios, para o desenvolvimento de habilidades pessoais e para o desenvolvimento da carreira acadêmica foram identificadas. Já ao relacionar a contribuição do PEE ao desenvolvimento de carreira e de negócios, foi percebida pouco mais de $54 \%$ de resposta positivas. Como o curso abordou constructos relacionados à gestão de negócios, pode ser que tenha influenciado maior quantidade de respostas remetendo a vida profissional. As respostas abaixo confirmam as afirmativas:

\footnotetext{
"Me ajudou no desenvolvimento de meu próprio negócio" (C23.32).

"Estamos passando por uma crise sem precedentes. Prestação de serviços em informática no setor de Saúde, tendo como principais clientes o setor público. O curso está ajudando a passar por esta crise com a grande redução do faturamento das empresas" (C96.32).

"Desenvolvi habilidades para poder prestar consultoria" (C129,32).
}

Do total de respostas, $11,2 \%$ dos egressos relacionaram o curso ao desenvolvimento de conquistas acadêmicas, apresentando melhorias do desempenho acadêmico e ganhos de titulação. Seguem algumas respostas:

\footnotetext{
"Melhorou a minha qualidade acadêmica" $(\mathrm{C} 40,32)$.

"Mestrado e Doutorado" (C167, 32).
}

É surpreendente que egressos de um programa de formação empreendedora apontem o desejo de realizar mestrado e doutorado como perspectiva de carreira. Este resultado sugere que a motivação para o curso pode não estar relacionada diretamente com o desejo de empreender, mas por um interesse difuso em participar de um curso oferecido gratuitamente por uma universidade federal reconhecida. Por outro lado, a EE desenvolve competências que auxiliam a pessoa a buscar alternativas para a vida, sendo a acadêmica uma opção e para Greenhaus (2010) os títulos adquiridos é uma forma de observar o sucesso na carreira. 
Outro grupo de pouco mais de $26 \%$ das respostas está relacionado ao desenvolvimento de habilidades pessoais. Foram citados melhoria de capacidade decisória, ampliação da capacidade de construir relacionamentos e aumento da percepção de oportunidades. Foi destacado ainda a elevação da autoconfiança e melhoria na forma de lidar com a vida entre outras questões. Algumas respostas foram:

\footnotetext{
“Adquiri mais confiança para falar em público e defender minhas ideias. E até fiz apresentação de canções próprias que nunca havia feito para o público" (C135,32).

"Aumentou muito minha capacidade de pensar e agir" $(\mathrm{C} 16,32)$.

"Saber lidar com as adversidades da vida" $(\mathrm{C} 110,32)$
}

\subsection{Contribuição do PEE para Carreira}

Quanto a contribuição do PEE para a carreira dos egressos, $81,1 \%$ dos respondentes indicaram que o curso contribuiu para o aperfeiçoamento de suas capacidades empreendedoras. Os resultados estão de acordo com Fayolle (2015) que evidencia a existência da contribuição dos PEEs para o desenvolvimento do comportamento empreendedor. A questão que mais obteve concordância entre os respondentes, $85,1 \%$, refere-se a aplicação dos conhecimentos que aprenderam no curso nas atividades profissionais. Esta percepção está alinhada com um dos objetivos do curso que é "desenvolver a capacidade empreendedora do egresso potencializando a sua inserção qualificada no mercado de trabalho". Mais da metade dos egressos, 52,9\%, reconhecem que se tornassem um empreendedor.

Ao responderem outro bloco de questões, foi identificado que $23 \%$ dos respondentes abriram seus próprios negócios ou fundaram uma ONG, depois da conclusão do curso. Neste caso, é provável que o restante dos respondentes que se consideram empreendedores se percebam como intraempreendedores. Ou seja, possivelmente parte dos respondentes que se consideram empreendedores abriram negócios próprios e a outra parte pode atuar como intraempreendedores. Possivelmente, o entendimento que os respondentes têm sobre o comportamento empreendedor seja convergente com o proposto por Lackéus (2015), que atribui ao empreendedor o papel de gerar valor para sociedade, por meios diversos e não apenas pela criação de um empreendimento. A proposta do curso está de acordo com HÄGG (2011) que entende ser possível ensinar empreendedorismo como um comportamento social.

Outro ponto observado é que quase $2 / 3$ dos respondentes, $61,1 \%$, reconhecem que o seu currículo se tornou mais atrativo e $46,7 \%$ declaram que aumentaram a empregabilidade. Embora o resultado sobre o aumento de empregabilidade tenha sido em menor concordância do que sobre a atratividade do currículo, há relação com os achados de Duval (2013), que afirma que os PEE ajudam a conquistar um emprego e tornar o currículo mais atrativo. Keena (2015) também afirma que há contribuição dos PEE para a empregabilidade dos egressos. Apesar de o objetivo do curso ser potencializar a inserção do egresso qualificado no mercado de trabalho, foi identificada que boa parte dos egressos não relaciona diretamente as competências desenvolvidas no curso com a melhor inserção no mercado de trabalho. Já em resposta ao questionamento sobre ter melhorado a capacidade analítica, 84,3\%, concordam que melhoraram este aspecto e mais de $81 \%$ percebem que a visão sobre como conduzir a carreira após o curso foi ampliada. Massi (2013) entende que o maior benefício do PEE é o desenvolvimento da personalidade profissional. Neste caso, as habilidades analíticas e de equipe são consideradas como um ganho. 
Outra questão que apresentou mais de $74 \%$ de concordância se refere a melhoria da capacidade de construir relacionamentos. Este resultado está de acordo com Elmuti (2012) que entende que os participantes dos PEE foram impactados positivamente, principalmente, em suas competências sociais. Ao serem indagados sobre se melhoraram a capacidade de se impor em situações sociais, ou seja, a capacidade de defender os seus próprios interesses e pontos de vista, mais de $2 / 3$, ou seja, $69,5 \%$ dos respondentes concordaram que melhoraram neste aspecto. A autoconfiança pode estar relacionada com a questão da defesa dos próprios interesses e, segundo Massi (2013), os participantes de um PEE percebem benefícios pessoais e profissionais e desenvolvem competências empreendedoras, como a autoconfiança.

\subsection{Contribuição do PEE para desenvolvimento de Competências Empreendedoras}

Foi percebido amplo reconhecimento do desenvolvimento das competências empreendedoras pelos respondentes, resultado que está de acordo com Fayolle (2015), que entende os PEE como desenvolvedores de competências empreendedoras. No entanto, as respostas positivas sobre competências empreendedoras desenvolvidas podem referir-se ao conhecimento sobre os construtos que as fundamentam e não necessariamente ao desenvolvimento da capacidade de colocar em prática tais competências. As diversas disciplinas do curso abordaram a base de conhecimento necessária ao desenvolvimento competências empreendedoras, entretanto, a limitação no método de ensino, com atividades mediadas por AVA, possivelmente não foram capazes de expor o estudante a um processo de aprendizagem que lhes permitissem colocar em prática tais conhecimentos de forma a exercitar o agir empreendedor. Isto significa que os egressos sabem de quais competências estava se falando, mas, possivelmente não experimentaram na prática, em sua plenitude.

Das competências avaliadas "Tornar-me mais persistente" foi a que obteve menor índice de concordância, 71,1\%. Já a busca de informações foi a competência que obteve maior índice de concordância (76,3\%), seguida de estabelecer metas $(72,8 \%)$ e de gerar mais Independência e autoconfiança $(70,5 \%)$. É interessante observar que as competências de maior concordância podem ser utilizadas na dimensão pessoal dos respondentes, o que está de acordo com a percepção de Pedrini (2017), que enfatiza o impacto da EE para as caractetísticas psicológicas e habilidades pessoais dos egressos.

\subsection{Contribuição do PEE para desenvolvimento de Competências Gerenciais}

$\mathrm{O}$ referido PEE analisado teve como proposta o desenvolvimento de competências gerenciais. As afirmações que compõem este bloco se basearam na escala proposta por Makhamed (2017) para avaliar itens relacionados à abertura e ao desenvolvimento de um negócio, que se mostrou útil para aferir o desenvolvimento de competência gerenciais desenvolvidas pelo PEE e conforme tabela 1, versaram sobre:

Tabela 1 - Itens do questionário sobre competências gerenciais

\begin{tabular}{l}
\hline 1. gestão estratégica, incluindo as competências de organização; \\
\hline 2. Gestão de risco; \\
\hline 3. Gestão de pessoas; \\
\hline 4. Competências de relacionamento; \\
\hline 5. Competência de oportunidade.
\end{tabular}

Fonte: elaborado pelas autoras 
Foi observado que mais de $70 \%$ dos respondentes concordaram com todos os itens propostos. O achado corrobora com o resultado de Elmuti (2012) que observa impacto positivo da EE nos cursistas ao analisar variáveis, como: i) satisfação, que se relaciona com o alcance de objetivos da empresa e alcance das necessidades de funcionários e empresários; ii) adaptabilidade, que se relaciona com a flexibilidade, vontade de mudar e inovar; iii) desempenho, que se relaciona com as vendas, rentabilidade e participação de mercado. Além disso, o curso propôs a articulação de conteúdos relacionadas a gestão empresarial.

A escala proposta por Makhamed (2017), utilizada para medir o desenvolvimento das competências gerenciais, apresenta o fator gestão estratégica como o mais relevante do questionário. As questões que avaliam a gestão estratégica e de organização mostram que da amostra de 143 respondentes, 87,8\% destes concordam que são capazes de tomar decisões estratégicas. O curso propõe uma formação com um "olhar" para o direcionamento estratégico, abordados na disciplina Estratégia e Marketing, estando os resultados de acordo com Elmuti (2012) que observa impacto positivo da EE com o alcance das estratégias empresariais. Outros itens avaliados que apresentaram mais de $70 \%$ de concordância foram aqueles em que o respondente disse ser capaz de: i) elaborar o planejamento estratégico da empresa; ii) analisar os resultados da empresa; iii) organizar o trabalho em função dos objetivos da empresa; iv) avaliar os progressos alcançados considerando os objetivos definidos; v) definir os objetivos da empresa a longo prazo.

No que se refere a gestão de risco, mais de $93 \%$ concordaram que colocaram em prática novas ideias na empresa. O segundo foi "explorar novas ideias para aplicar futuramente na empresa" com pouco mais de $91 \%$ de concordância. As respostas podem ter sido influenciadas pelo resultado da proposta do projeto pedagógico do curso que visa a capacitação de um profissional que busque empreender em soluções inovadoras. Importante destacar que um dos resultados esperados de um PEE é justamente o desenvolvimento da mentalidade empreendedora, que está relacionado com a capacidade de colocar ideias em prática. Deste bloco de questões, dois itens mantiveram o mesmo índice de concordância, 88,4\%, que foram "Enfrentar os problemas de diferentes formas" e "Enfrentar os problemas como sendo oportunidades". A busca de oportunidade foi trabalhada no curso.

Os menores índices de concordâncias estão relacionados ao risco. Foi observado que $79,8 \%$ dos respondentes são capazes de correr riscos moderados relacionados com o trabalho É reconhecida a formação de competências direcionadas para correr riscos no campo da EE (ARPIAINEN, 2017). A percepção dos respondentes está de acordo com Dias-Garcia (2015) que aponta os participantes dos PEE percebendo mais dificuldades ambientais, como por exemplo a percepção de risco.

Ao avaliar o conhecimento sobre gestão de pessoas, 92,8\% concordaram que melhoraram a capacidade de coordenar tarefas. Este tema foi tratado nas unidades curriculares "Liderança e Gestão de Pessoas", e "Gestão Empreendedora por Processos". Os achados de Elmuti (2012) ressaltam que os PEE impactam nas competências sociais, que por análise são importantes para quem coordena tarefas. Além disso, Duval-Couetil (2012) mostra que os PEE ampliam nos cursistas a propensão para aprendizagem que envolve habilidades como análise de mercado e comunicação comercial. Embora o PPC do curso apresente a proposta do desenvolvimento de habilidades e valores para formar, inspirar e coordenar equipes, a liderança foi entendida como menos desenvolvida entre as questões respondidas, $85,6 \%$. 
Ao analisar as questões sobre competências de relacionamento foi observado que quase todos os itens foram avaliados com mais de $90 \%$ de concordância. Os resultados confirmam que os PEE contribuem para o desenvolvimento de competências sociais, o que está de acordo com os achados de Elmuti (2012). O curso analisado incentivou o trabalho em grupo e apresentou a importância da rede de contatos para a formação de um empreendedor. Possivelmente, os 92,8\% dos respondentes que concordam que estabelecem bons contatos pessoais tenham sido influenciados pelo conteúdo do curs. Há concordância com os achados de Massi (2013) que entende o maior benefício do PEE sendo o desenvolvimento da personalidade profissional, como as habilidades de equipe.

Já ao serem perguntados sobre se são capazes de se comunicar de forma correta, $89,2 \%$ concordaram com o desenvolvimento desta competência. A unidade curricular Técnicas de Comunicação e Negociação pode ter contribuído para esta construção de competência social, visto que propôs trabalhar conceitos e técnicas de comunicação e negociação em situações de cooperação ou conflito, convencimento ou construção de consenso e de compromisso, geração ou validação de ideias. Mais de $92 \%$ dos entrevistados percebem que são capazes de interagir com os outros. Os dados estão de acordo com Carvalho (2015), que percebe a criação e capacidade do trabalho em equipe como fatores positivos do PEE que influenciam o projeto de vida dos egressos, envolvendo dimensões pessoais e profissionais.

Um total de $91 \%$ dos respondentes concordou que são capazes de "identificar as necessidades dos clientes", enquanto $85,7 \%$ concordaram que "satisfazem de forma eficaz as necessidades dos clientes". Estes resultados estão de acordo com Duval-Couetil (2012) que informa que os participantes do PEE concordam que a $E E$ aumentou suas habilidades para comunicação comercial.

Do total de respondentes $83,1 \%$ concordaram que melhoraram a capacidade de "desenvolver novos produtos e serviços. Este resultado pode ter sido influenciado pelo incentivo do curso para que os cursistas refletissem sobre novos projetos de produtos e serviços. Outros $86,3 \%$ dos respondentes concordaram que passaram a "identificar boas oportunidades de negócios". Para Ladyga (2015), uma pessoa empreendedora tem a capacidade de perceber oportunidades e a análise de oportunidades foi proposta pelo curso.

\subsection{Contribuição do PEE para desenvolvimento de Competências Intraempreendedoras}

Os 94 respondentes que eram empregados em organizações privadas ou públicas responderam a todos os blocos de questões, incluindo as questões específicas sobre competências intraempreendedoras pretensamente desenvolvidas pelo curso. Foi observado que a grande maioria $(87,2 \%)$ afirma que coloca "em prática a iniciativas para avaliar e refinar novas ideias", ou seja, parecem exercitar a criatividade, e percebe "as vantagens da inovação para a organização" (92,6\%). Entretanto, quando perguntados se promovem a inovação na área em que atuam, um contingente menor (72\%) concorda com a afirmação. Os resultados apontam para uma elevada sensibilização dos egressos para o papel da inovação para as organizações, apesar de um número menor de respondentes assumir para si o papel de inovador. Vale ressaltar que a competência para a inovação está presente nos empreendedores (LADYGA, 2015) e o PPC do curso propõe a busca por soluções inovadoras. Os resultados confirmam o pretenso desenvolvimento da criatividade entre os respondentes, o que está em 
concordância com Kovesi (2017) que apresenta a criatividade como uma competência importante para o desenvolvimento da EE.

Sobre o entendimento das operações da empresa, 91,5\%, afirmam buscar "entender em profundidade as operações que a empresa ou organização realiza". Competências desenvolvidas pelo PEE, como a busca de informações, podem ter contribuído para o despertar do entendimento das operações da empresa/organização.

O PEE analisado estimula que o estudante planeje e monitore o seu planejamento, envolvendo as dimensões pessoal e profissional. Neste caso, é proposto que os cursistas ocupem posições desejadas tomando as direções da própria vida e estimulando, portanto, que exerçam o trabalho com entusiasmo. Zikic (2015) apresenta a paixão pelo trabalho como uma característica presente na carreira empreendedora, o que é confirmado por quase $80 \%$ dos respondentes que concordam que são entusiasmados com o próprio trabalho. Outra temática abordada foi a mudança. Para Ladyga (2015), os empreendedores têm capacidade de se adaptar às condições de mudança. Ao responderem sobre as novas demandas de trabalho, 86,2\% concordam que lidam bem com novas demandas de trabalho. Quase $84 \%$ dos respondentes afirmam encorajar a participação dos seus colegas de trabalho. As respostas sobre mudança e equipe estão interligadas ao desenvolvimento de personalidade profissional e foram respondidas com níveis de concordâncias muito próximos, cerca de $80 \%$ de concordância, o que corrobora com Massi (2013) que entende como maior benefício do PEE o desenvolvimento da personalidade profissional, como as habilidades analíticas e de equipe. Neste caso, o PEE analisado parece ter contribuído com o desenvolvimento da personalidade profissional dos egresso.

\section{Conclusões}

A pesquisa objetivou identificar a contribuição da EE para a carreira de egressos de um programa desenvolvido com este objetivo. Os resultados indicam que os egressos, de maneira geral, concordam que o programa em tela contribuiu para o seu desenvolvimento pessoal e profissional. A percepção dos respondentes sobre as competências empreendedoras e gerenciais desenvolvidas pelo curso foi de concordância superior a $70 \%$ das respostas em todos os itens propostos. Foram avaliadas questões sobre gestão estratégica, incluindo as competências de organização, gestão de risco, gestão de pessoas, competências de relacionamento e competência de oportunidade. As questões sobre tomada de decisão estratégica, apresentadas como as mais relevantes do questionário, apontaram que $87,8 \%$ dos respondentes concordam que são capazes de tomar decisões estratégias. Este resultado pode ter sido influenciado pela formação do curso que propôs um "olhar" para o direcionamento estratégico.

Ao buscar compreender se o curso contribuiu para que o egresso se tornasse um empreendedor, mais de $52 \%$ dos egressos reconhecem esta contribuição. Foi percebido que mais de $23 \%$ dos respondentes abriram seus próprios negócios ou fundaram uma ONG depois da conclusão do curso. É possível que os demais respondentes que se consideram empreendedores se perceba como intraempreendedores. Possivelmente, o entendimento que os respondentes têm sobre o comportamento empreendedor seja convergente com o proposto por Lackéus (2015), que atribui ao empreendedor o papel de gerar valor para sociedade por 
meios diversos, e não apenas pela criação de um empreendimento, sendo a orientação conceitual sobre empreendedorismo trabalhada neste PEE.

Os empregados do setor privado ou público, ao serem indagados sobre as competências intraempreendedoras, responderam questões referentes a inovação, criatividade, entendimento sobre as operações da empresa, encorajamento da participação dos colegas de trabalho e capacidade de se adaptar as condições de mudança. Foi observada uma elevada sensibilização dos egressos para o papel da inovação para as organizações, apesar de um número menor de respondentes assumir para si o papel de inovador. Os respondentes declaram ter desenvolvido sua criatividade e aprendido sobre processos operacionais.

Ao sintetizar as três principais contribuições do curso para a vida pessoal dos egressos empregados do setor público e privado, foram apontados: capacidade de promover mudanças, busca de novos desafios e novas ideias, identificação de oportunidade, capacidade de inovar, autoconhecimento e melhoria contínua entre outras. Enquanto ao analisar a contribuição do curso para a vida profissional os resultados evidenciaram que os egressos percebem esta contribuição como uma ampliação da visão para o mercado de trabalho, contudo, ao serem perguntados sobre se aumentaram a empregabilidade, menos da metade dos respondentes, 46,7\%, reconhecem este aumento. Como a maior parte dos respondentes, 60,7\%, são empregados do setor privado ou público, o resultado parece contraditório, visto sugerir que os egressos valorizaram a formação, pois aprenderam sobre temas que não conheciam, mas parecem ter menor clareza sobre a contribuição direta das novas competências adquiridas para sua carreira. Desta forma, foi observado que apesar de o objetivo do curso ser potencializar a inserção do egresso qualificado no mercado de trabalho, boa parte dos egressos parece não relacionar diretamente as competências desenvolvidas no curso com a melhor inserção no mercado de trabalho. Uma proposta para ampliação da visão sobre o mercado de trabalho e sobre a própria carreira é incluir conteúdos abordando a construção do plano de desenvolvimento profissional, a partir da análise de características pessoais e do mercado.

O PEE parece ter contribuído para desenvolvimento da personalidade profissional, sendo a personalidade profissional um item de maior benefício para os egressos. Outros resultados relacionados a carreira foram apontados, como: $61,1 \%$ dos egressos, reconhecem que o seu currículo se tornou mais atrativo após o curso, $84,3 \%$ reconhecem ter melhorado a capacidade analítica, $74 \%$ reconhecem ter melhorado a capacidade de construir relacionamentos, $69,5 \%$ melhoraram a capacidade de se impor em situações sociais.

Em síntese, a pesquisa mostrou de forma geral, que o egresso avalia positivamente o PEE, porém, não tem clareza sobre como as competências desenvolvidas contribuem para a sua carreira. As competências desenvolvidas pelo PEE parecem não ter contribuído diretamente para aumentar a empregabilidade dos egressos em um contexto de recessão e desemprego, uma vez que houve redução dos empregados em empresas privadas. Entretanto, o PEE parece ter contribuído para que os egressos se reposicionassem no mercado de trabalho seja como MEI ou como servidor público. Importante destacar que esta pesquisa foi realizada após um encolhimento do PIB brasileiro de quase $10 \%$, e elevação substancial da taxa de desemprego, e ainda assim boa parte dos egressos mantiveram-se empregados. No Rio de Janeiro o impacto da crise econômica foi ainda maior que no restante do Brasil. As competências gerenciais desenvolvidas pelo programa podem ter contribuído para o aumento da empregabilidade dos egressos que participaram de processos de seleção para cargo público. 
Por fim, continua sendo um desafio importante da área de EE analisar a contribuição de programas construídos com visão mais ampliada do empreendedorismo baseado na geração de valor que, diferentemente de programas focados na criação de empresa, resultam em desenvolvimento de ação empreendedora que se espalha em diversos contextos sociais. No caso analisado, uma das conclusões que se chega é que os egressos percebem valor em terem participado do curso, mas não sabem como este valor foi apropriado em suas carreiras.

Uma proposta para a realização de novas pesquisas é aprofundar o entendimento sobre como os egressos apropriam-se das competências desenvolvidas por meio de PEE, estruturado na perspectiva do empreendedorismo como elemento gerador de valor social, conforme definido por Lackéus (2015).

\section{Referências Bibliográficas}

ARPIAINEN, R.; KURCZEWSKA, A. Learning risk-taking and coping with uncertainty through experiential, team-based entrepreneurship education. Industry and Higher Education, v. 31, n. 3, 1 jun. 2017, p. 143-155, 2017.

ARTHUR, M. B.; ROUSSEAU, D. M. The boundaryless career as a new employment principle for a new organizational era. p. 3-22, 1996.

BARDIN, L. Análise de conteúdo. Lisboa: Edições 70, 2006.

BARUAH, B.; WARD, A. Metamorphosis of intrapreneurship as an effective organizational strategy. International Entrepreneurship and Management Journal, v. 11, n. 4, p. 811-822, dez. 2015.

CARVALHO, L.; COSTA, T.; MARES, P. A success story in a partnership programme for entrepreneurship education: Outlook of students perceptions towards entrepreneurship. International Journal of Management in Education. v. 9, n. 4, p. 444-465, 2015.

CALLANAM, G. A.; ZIMMERMAM, M. To be or not to be an entrepreneur: applying a normative model to career decisions. Journal of Career Development. v. 43, p.447-461, 2016.

CARREIRA. Dicionário Online do Aurélio, 26 jun. 2017. Disponível em: 〈https://dicionariodoaurelio.com/eficaz〉. Acesso em: 16 Fev. 2018.

CHANLAT, J. F. Quais carreiras e para qual sociedade? Revista Administração de empresas, São Paulo, v. 36, n. 1, p. 13-20, mar. 1996.

DIAZ-GARCIA, C.; SAEZ,-MARTINEZ, F.; JIMENEZ-MORENO, J. Assessing the impact of the "Entrepreneurs" education programme on participants' entrepreneurial intentions. Rusc-universities and Knowledge Society Journal, v. 12, n.3, p. 17-31, 2015.

DOUGLAS, E. J.; FITZSIMMONS,J. R. Intrapreneurial intentions versus entrepreneurial intentions: distinct constructs with different antecedentes. Small Business Economics, v. 41, n. 1, p. 115-132, jun. 2013.

DUVAL-COUETIL, N.; WHEADON, J. The value of entrepreneurship to recent engineering graduates: a qualitative perspective. Conferência: 43rd Annual Frontiers in Education Conference (fie), Univ Oklahoma, Coll Engn, Oklahoma City, Oct 23-25, 2013.

DUVAL-COUETIL, N.; REED-RHOADS, T.; HAGHIGHI, S. Engineering students and entrepreneurship education: Involvement, attitudes and outcomes. International Journal of Engineering Education, v. 28, n. 2, p. 425-435, 2012.

ELMUTI, D.; KHOURY, G.; OMRAN, O. Does entrepreneurship education have a role in developing entrepreneurial skills and ventures' effectiveness? Journal of Entrepreneurship Education, v. 15, p. 83-98, 2012. 
FARRUKH, M.; YIN, C. W.; MANSORI, S. Intrapreneurial behavior: an empirical investigation of personality traits. Management $\&$ marketing-challenges for the knowledge society, v. 11, n. 4, p. 597-609, Dez. 2016.

FAYOLLE, A. Personal views on the future of entrepreneurship education, Entrepreneurship \& Regional Development: An International Journal, v. 25, n. 7-8, p. 692-701, 2013.

FAYOLLE, A.; GAILLY, B. The impact of entrepreneurship education on entrepreneurial attitudes and intention: Hysteresis and persistence. Journal of Small Business Management, v. 53, p. 75-93, 2015.

FILION, L. J. Entendendo os intraempreendedores como visionistas. Revista de Negócios, v. 9, n. 2, p. 65-80, 2004.

GIBB, A. A. The Enterprise Culture and Education. Understanding Enterprise Education and Its Links with Small Business, Entrepreneurship and Wider Educational Goals. International Small Business Journal. v. 11, n. 3, p.11-37, 1993.

GREENHAUS， J.H.; CALLANAN， G.A.; GODSHALK， V. M. Career Management, 4a.ed. Thousand Oaks, CA: Sage. 2010.

HAIR JUNIOR, J. F; ANDERSON, R. E; TATHAN, R. L; BLACK, W. C. Análise Multivariada de Dados. 5.ed. Porto Alegre: Bookman, 2005.

JASKIEWICZ, P. et al. Paid Employee or Entrepreneur? How Approach and Avoidance Career Goal Orientations Motivate Individual Career Choice Decisions. Journal of Career Development, v. 43, n. 4, p. 349-367, Ago. 2016.

KAKOURIS, A. On Initial Implementations of Innovation and Entrepreneurship Courses: A Case Study for Undergraduates at the University of Athens. Conferência: 3rd European Conference on Entrepreneurship and Innovation Local: Univ Winchester, Winchester, Inglaterra, p. 15-16, set. 2008.

KEENA, L.; SIMMONS, C. Rethink, Reform, Reenter: An Entrepreneurial Approach to Prison Programming. International Journal of Offender Therapy and Comparative Criminology, v. 59, n. 8, p: 837-854, 2015.

KOLADE, O. Venturing under fire: Entrepreneurship education, venture creation, and poverty reduction in conflict-ridden Maiduguri, Nigeria. Education and Training, v. 22, 2018.

KOVESI, K. The changing face of entrepreneurship education for engineering students in France. Conferência: 8th Ieee Global Engineering Education Conference (educon), Atenas: Grécia, p. 25-28, 2017.

LACKEUS, M. Entrepreneurship in Education - What, Why, When, How. Entrepreneurship 360 Background Paper, OECD, France, 2015.

LADYGA, E. Entrepreneurship as a basis of self-management on the way to career. Polish Journal of Management Studies, v. 12, n. 1, p. 87-95, 2015.

LANDSTRÖM, H.; HARIRCHI, G.; ASTRÖM, F. Entrepreneurship: exploring the knowledge base. Research Policy, v. 41, n. 7, p. 1154-1181, 2012.

LEE-ROSS, D. Personality characteristics of the self-employed: A comparison using the World Values Survey data set. Journal of Management Development, v. 34, n. 9, p. 1094-1112, 2015.

LOPES, R. M. A. Ensino de Empreendedorismo no Brasil: Panorama, tendências e melhores práticas. $1^{\mathrm{a}}$ ed. Rio de Janeiro: Alta Books. Ed., 2017. 
LAGES, M.; MARQUES,C. S.; FERREIRA, J. J. M.; et al. Intrapreneurship and firm entrepreneurial orientation: insights from the health care service industry. International Entrepreneurship and Management Journal, v. 13, n. 3, p. 837-854, set. 2017.

MARIANO, S.; MAYER, V. F. Empreendedorismo: fundamentos e técnicas para a criatividade. Rio de Janeiro: LTC, 2012.

MASSI, L. et. al. Internships and Undergraduate Research: Impact, Support, and Institutionalization of an NSF S-STEM Program through Partnerships with Industry and Funding from Federal and Local Workforce Agencies. Conferência: ASEE Annual Conference, local: Atlanta, GA, jun. 2013.

MAKHAMED, Y; BENDASSOLLI, P. Evidências de Validade de um Inventário de Competências Empreendedoras para Empresários Juniores. Psico-USF, Campinas, v. 22, n. 2, p. 285-297, Mai. 2017 Disponível em: $<$ http://www.scielo.br/scielo.php?script=sci_arttext\&pid=S141382712017000200285\&lng=en\&nrm=iso>. Accesso em: 20 Jan. 2019.

MCCLELLAND, D. C. Characteristics of Successful Entrepreneurs. The Journal or Creative Behavior, v. 21, n. 3. p. 219-233, 1987.

MIRVIS, P. H; HALL, D. T. Psychological success and the boundaryless career. The boundaryless career. A new employment principle for a new organizational era, p. 237-255, 1996.

MORAES, J. et al. Uma proposição Espistêmica quadripolar do constructo empreendedorismo. REGE Revista de Gestão, São Paulo, v. 22, n. 4, p. 545-564, fev. 2016.

MOBERG, K. Assessing the Impact of Entrepreneurship Education. 2014. 238f. Tese de Doutorado. Copenhagen Business School. Dinamarca, 2014.

PEDRINI, M.; LANGULLA, V.; MOLTENI, M. Do entrepreneurial education programs impact the antecedents of entrepreneurial intention? An analysis of an entrepreneurship MBA in Ghana. Journal of Enterprising Communities-people and Places of Global Economy, v. 11, n.3, Ed. especial: SI, p. 373-392, 2017.

PNAD. Taxa de desocupação. Disponível em:< https://agenciadenoticias.ibge.gov.br/agencia-sala-de-imprensa/2013-agencia-denoticias/releases/25092-pnad-continua-taxa-de-desocupacao-e-de-12-0-e-taxa-de-subutilizacao-e24-8-no-trimestre-encerrado-em-junho-de-2019> Acesso em: 26 Out. 2019.

RIBEIRO, C. V. S.; MANCEBO, D. O servidor público no mundo do trabalho do século XXI. Psicologia: Ciência e Profissão, Brasília, v. 33, n. 1, p. 192-207, 2013 . Acesso em: $<$ http://www.scielo.br/scielo.php?script=sci_arttext\&pid=S1414-

98932013000100015\&lng=en\&nrm=iso >. Acesso em: 20 Mai. 2019.

WOO, H.R. Personality traits and intrapreneurship: the mediating effect of career adaptability. Career Development International. v. 23, n. 2, p. 145-162, 2018.

ZHAO, H., G. E.; HILLS, and S. E. SEIBERT. The Mediating Role of Self-Efficacy in the Development of Entrepreneurial Intentions. Journal of Applied Psychology, v. 90, n. 6, p. 12651272, 2005.

ZIKIC, J.; EZZEDEEN, S. Towards a more integrated view of entrepreneurial careers Qualitative investigation of the three forms of career capital and their relationships among high tech entrepreneurs. International Journal of Entrepreneurial Behaviour \& Research, v. 21, n. 6, p. 756-777, mai. 2015. 